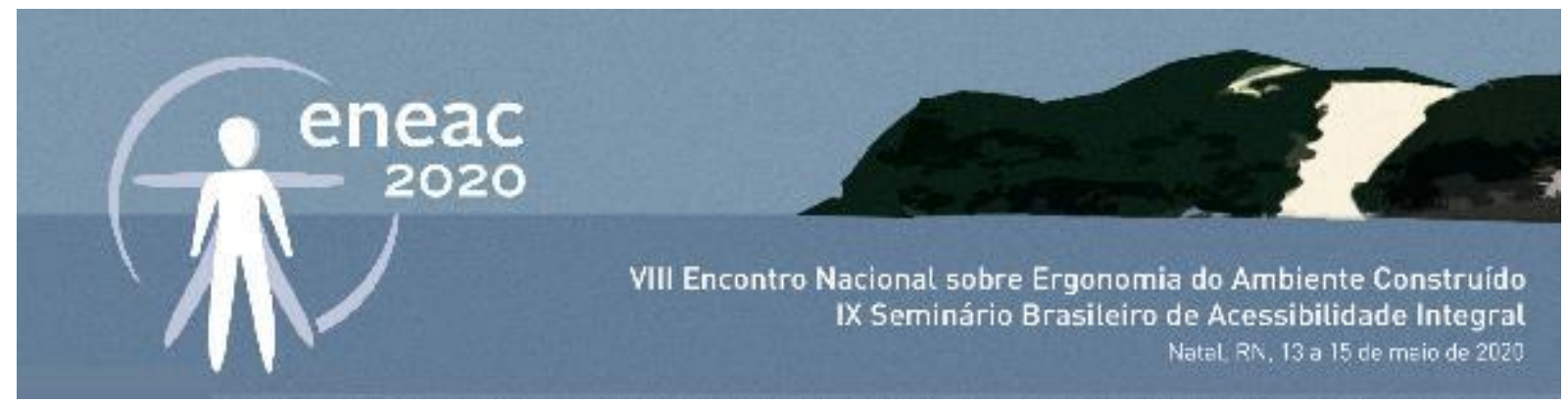

\title{
Avaliação ergonômica de uma área de convivência em ambiente universitário - Mezanino do Centro de Artes e Comunicação da UFPE
}

\section{Ergonomic evaluation of a university living area - Mezzanine of the UFPE Arts and Communication Center}

\author{
ANTÔNIO SEVERINO FELIX NETO \\ Graduando em Arquitetura e Urbanismo, Universidade Federal de Pernambuco, \\ antoniosfelixneto@hotmail.com \\ MARIA LUIZA ROCHA MARIZ VALENÇA \\ Graduanda em Arquitetura e Urbanismo, Universidade Federal de Pernambuco, \\ malumariz12@gmail.com \\ MATHEUS HENRIQUE RODRIGUES DE MEDEIROS \\ Graduando em Arquitetura e Urbanismo, Universidade Federal de Pernambuco, \\ mathenriquee97@gmail.com \\ THAIS SANTOS COSTA \\ Graduanda em Arquitetura e Urbanismo, Universidade Federal de Pernambuco, \\ thaisscosta.26@gmail.com
}

\section{RESUMO}

O presente artigo tem como finalidade avaliar ergonomicamente o Mezanino do Centro de Artes e Comunicação (CAC), localizado no campus Recife - Universidade Federal de Pernambuco. A análise foi baseada em dados coletados in loco de temperatura, ventilação, umidade, iluminação, qualidade e disposição do mobiliário e também a limpeza e conforto do ambiente. Além disso, foi realizada uma análise de fatores subjetivos, como conforto psicológico, feita através da aplicação de formulários digitais com frequentadores do local. A partir disso, constatou-se uma série de fatores que interferem na utilização plena do ambiente, tais como: falta de acessibilidade e ventilação adequada, ocorrência de ruídos em determinados horários do dia, desconforto térmico, desconforto psicológico causado pelas cores, pelo mobiliário inadequado e pela falta de limpeza constante do local. Este artigo propõe ainda medidas para solucionar parte dos problemas identificados no local, a fim de torná-lo mais confortável, acessível e agradável para o público que o frequenta.

PALAVRAS-CHAVE: ergonomia; conforto ambiental; mezanino.

ABSTRACT (150 to 250 words)

The following article aims to ergonomically evaluate the Mezzanine of the Arts and Communication Center (CAC), located on Recife's Federal University of Pernambuco campus. The analysis was based 


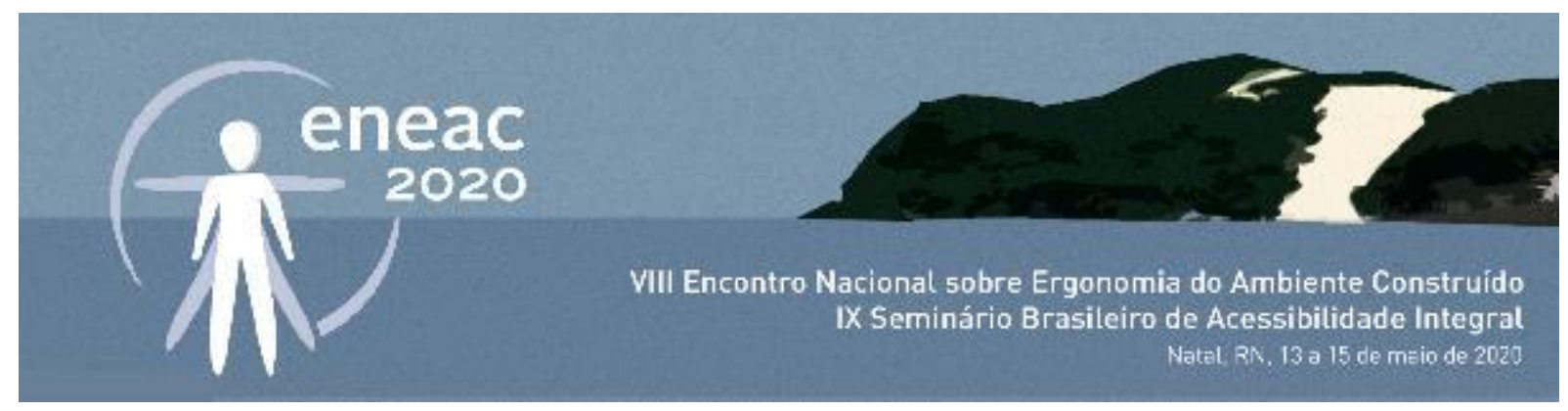

on in loco collected data of temperature, ventilation, humidity, lighting, quality and layout of the furniture and also the cleanliness and comfort of the environment. In addition, an analysis of subjective factors, such as psychological comfort, was carried out through the application of digital forms with daily users of the place. From that, it was found a series of factors that interfere in the full use of the environment, such as: lack of accessibility and adequate ventilation, occurrence of noise at certain times of the day, thermal discomfort, psychological discomfort caused by colors, by inadequate furniture and the lack of constant cleaning of the place. This article also proposes measures to solve part of the problems identified in the place, in order to make it more comfortable, accessible and pleasant for the public that frequents it.

KEYWORDS: ergonomics; environmental comfort; mezzanine.

\section{INTRODUÇÃO}

Este estudo de caso foi realizado no Centro de Artes e Comunicação (CAC) da Universidade Federal de Pernambuco, Campus Reitor Joaquim Amazonas, em Recife capital do Estado de Pernambuco. $O$ prédio que abriga o centro é uma edificação em estilo brutalista, datada de 1973, de autoria do arquiteto Reginaldo Esteves. O centro hoje abriga os departamentos de Arquitetura e Urbanismo, Ciência da informação, Comunicação Social, Design, Expressão gráfica, Letras e Música. Para acomodar todas essas atividades, o centro passou por diversas ampliações que modificaram expressivamente o projeto original. Muitos problemas são acarretados pela idade, intervenções posteriores e estado precário de conservação da edificação, como comprometimento da ventilação natural, acessibilidade e integridade física dos espaços e mobiliários.

A qualidade de um ambiente, de acordo com as necessidades do usuário, é imprescindível para o bom funcionamento de um projeto arquitetônico. A avaliação ergonômica de ambientes construídos, em uso, serve para avaliar quantitativamente os diversos fatores associados à interação entre 0 usuário, como sujeito principal, o mobiliário, o equipamento e o trabalho em si (VILLAROUCO, 2011, p.30). As áreas de convivência têm papel importante no contexto universitário por serem palco de manifestações, trocas culturais e políticas, espaços de descanso e de contemplação da paisagem e pontos de encontro para os usuários do espaço, sendo esses estudantes ou não. O mezanino, como espaço de estar e convivência que atende diversos cursos do CAC, deve contar com a harmonia entre esses fatores para que funcione tal qual foi pensada a sua função. Percebe-se que esse ambiente, em sua condição de uso atual, não atende bem às necessidades dos seus usuários.

O mezanino do CAC, em particular, mais do que um espaço de encontro, também funciona como refeitório para os alunos, uma vez que o edifício não conta com espaço destinado a refeições, que não seja o restaurante do centro, estabelecimento particular localizado abaixo desse espaço. Além disso, ele dá suporte às reuniões dos Diretórios Acadêmicos (DAs), que têm suas salas lindeiras a esse ambiente e ambos (o mezanino e os DAs) possuem um acesso comum. Alguns alunos ainda aproveitam as mesas para desenvolver suas atividades acadêmicas de leitura, estudo e trabalhos manuais (maquetes, pinturas e desenhos). $O$ acesso ocorre somente por meio de uma escada de grande fluxo impedindo que cadeirantes e pessoas com outros problemas de mobilidade acessem o 


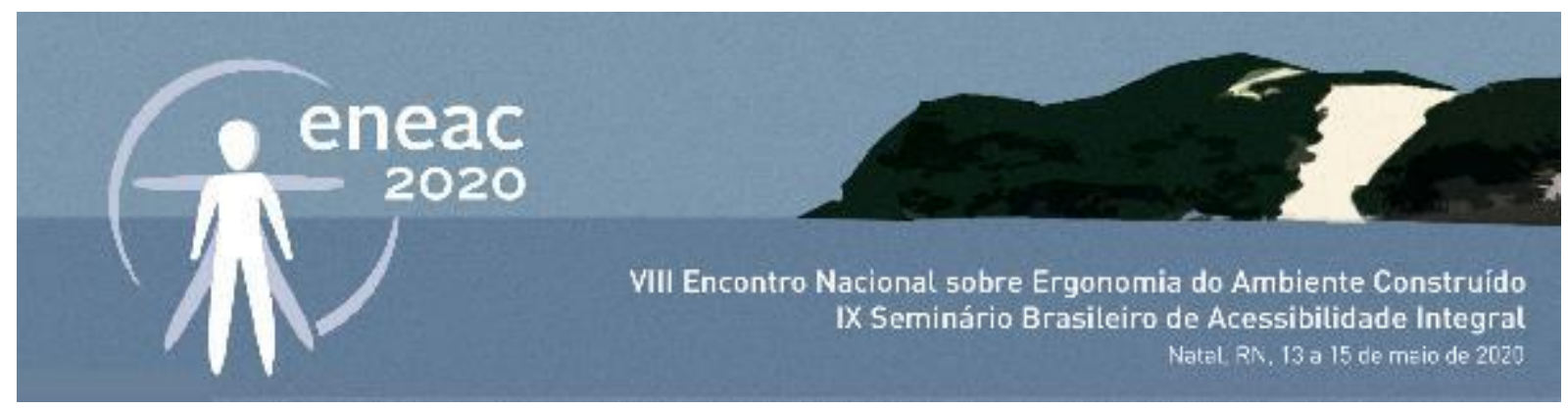

ambiente sozinhas. Além disso, o ambiente é bastante quente nos períodos de maior uso, ruidoso e tem mobiliário inadequado, comprometendo o conforto ambiental e ergonômico do ambiente.

Objetivou-se analisar ergonomicamente esse ambiente, através da Metodologia Ergonômica do Ambiente Construído (MEAC), proposta por Villarouco (2008), identificando os fatores que não proporcionam a interação usuário-ambiente adequada à atividade executada.

\section{OBJETIVO E METODOLOGIA}

O presente artigo tem como objetivo realizar uma análise ergonômica de um ambiente construído, desenvolvendo um estudo sobre as condições térmicas, acústicas, lumínicas e de percepção dos usuários do mezanino do Centro de Artes e Comunicação.

Para o desenvolvimento da análise ergonômica do mezanino do CAC foi utilizada a Metodologia para Análise do Ambiente Construído (MEAC), desenvolvida por Villarouco (2008). A escolha desta metodologia de análise se deu a partir da necessidade de uma avaliação não apenas físico-espacial, mas que também levasse em consideração as percepções do usuário em relação ao ambiente construído.

A MEAC se desenvolve a partir de dois blocos de análise. O primeiro bloco trata das análises físicas, formado por análise global do ambiente, identificação da configuração ambiental e avaliação do ambiente em uso; e o segundo bloco avalia as questões cognitivas, formado pela análise da percepção ambiental do usuário. A partir dessas análises, foram desenvolvidos o diagnóstico ergonômico e as propostas de intervenção do ambiente.

A análise global do ambiente foi realizada a partir de: visitas ao ambiente, observações do ambiente em uso, conversas com os usuários e registros fotográficos, com a intenção de promover reconhecimento inicial do espaço a ser estudado e de registrar eventuais problemas relacionados ao uso do ambiente. Na identificação da configuração ambiental foram levantadas as condições ambientais (ruído, temperatura, iluminação), condições físicas (dimensões dos mobiliários, layout, materiais de revestimento), e condições de acessibilidade do ambiente. Para a aferição das características ambientais, foram realizadas medições onde se utilizaram os seguintes instrumentos: termohigrômetro, marca Instrutherm, que registrou a temperatura do ar e a umidade relativa do ar, termoanemômetro, marca Instrutherm, que foi utilizado no registro da velocidade dos ventos, a direção dos ventos foi anotada a partir de uma bússola; utilizou-se o luxímetro, marca Minipa, para medir a iluminância do ambiente interno e o decibelímetro, marca Minipa, nas medições dos níveis de intensidade dos ruídos no local. A avaliação do ambiente em uso consistiu em observar o ambiente em uso, elencando as atividades nele exercidas pelos usuários e se estas estão sendo realizadas de maneira otimizada além de registrar os principais os fluxos no ambiente.

Na percepção ambiental do usuário, buscou-se investigar as percepções em relação ao ambiente com a aplicação de formulário online destinado aos usuários que frequentam o espaço. Foi utilizada a Constelação de Atributos, idealizada por Moles, em 1968, posteriormente desenvolvida por Ekambi-Schmidt em 1974 e utilizada nas pesquisas de Villarouco para representar os resultados. A constelação consiste em atribuir características ao ambiente a partir da narrativa dos usuários coletada em entrevistas e pesquisas. São elaboradas perguntas subjetivas, com respostas abertas e o 


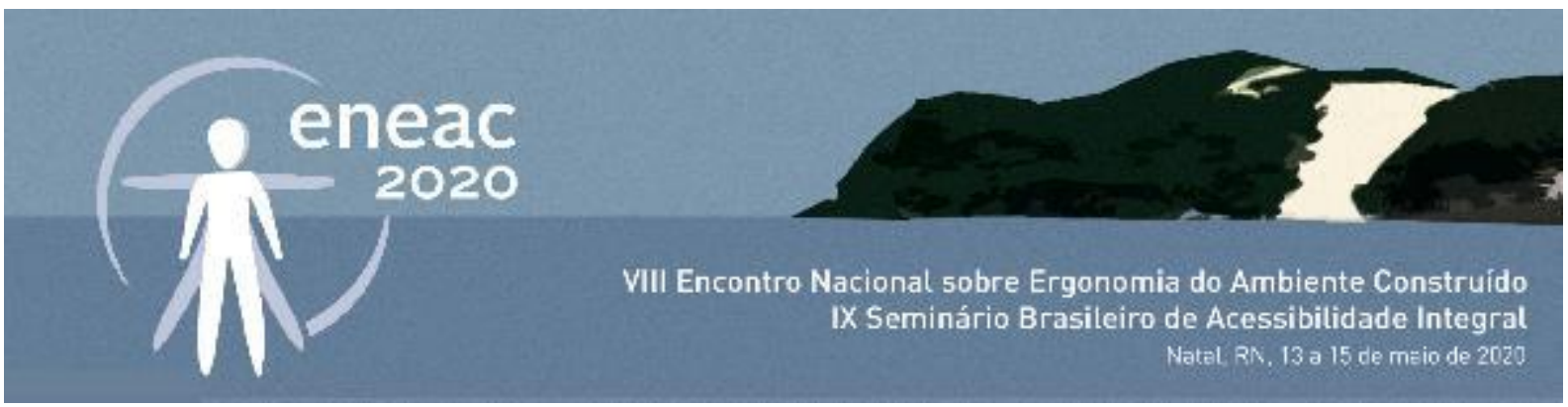

objetivo é identificar e enumerar os atributos relacionados à percepção do ambiente pelo usuário. $O$ Diagnóstico Ergonômico do Ambiente ocorreu após o levantamento dos dados, e apontou a situação geral do ambiente analisado, identificando os seus problemas, suas fraquezas e suas potencialidades. Nas proposições ergonômicas para o ambiente, foram feitas recomendações ergonômicas procurando responder aos resultados individuais e globais do diagnóstico ergonômico do ambiente.

\section{AVALIAÇÃO ERGONÔMICA}

\section{Análise dos aspectos físicos}

O mezanino do CAC (Figura 1) configura-se como um espaço multiuso. É utilizado como ponto de encontro dos estudantes, para conversar, realizar refeições ou fazer atividades acadêmicas. Dessa forma, o local pode apresentar diferentes características ao longo do dia.

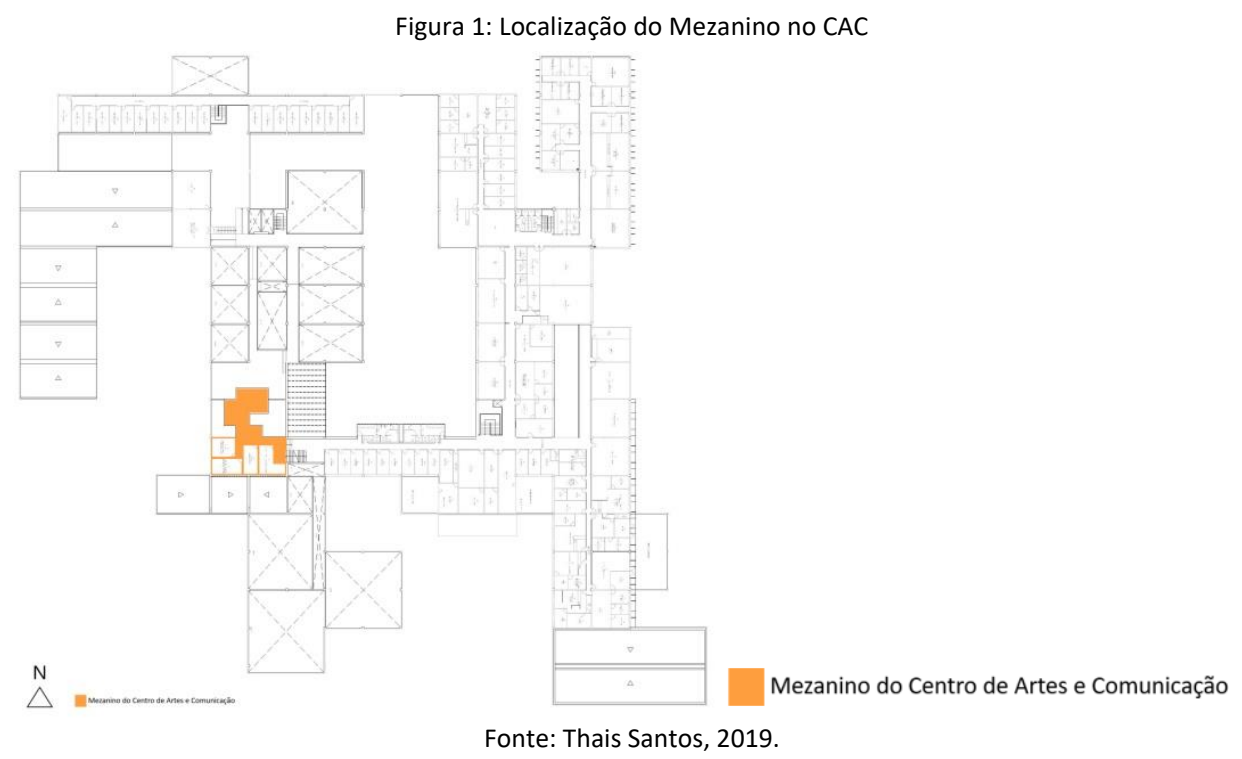

Durante o dia inteiro, o mezanino configura-se como um ambiente desconfortável do ponto de vista térmico, como será apresentado de forma mais detalhada adiante, o que faz com que o local dificilmente abrigue atividades de duração prolongada.

O mobiliário do local (Figuras 2 e 3 ) também é outro fator que corrobora para que os alunos não permaneçam por muito tempo no local. As mesas são antigas, riscadas e mal conservadas. As cadeiras, provavelmente reaproveitadas de outros ambientes, também se encontram na mesma situação, além de muitas estarem quebradas. A disposição do mobiliário muda durante o dia (Figuras 4 e 5), fato que demonstra a falta de eficiência do mesmo para atender as necessidades de uso do usuário. Além disso, os guarda-corpos do mezanino, assim como em todo o CAC, medem $0,90 \mathrm{~m}$, que era a antiga recomendação da época em que o prédio foi construído. No entanto, segundo a ABNT/NBR 14718, recomenda-se que a altura mínima do guarda corpo deve ser de 1,1m. 


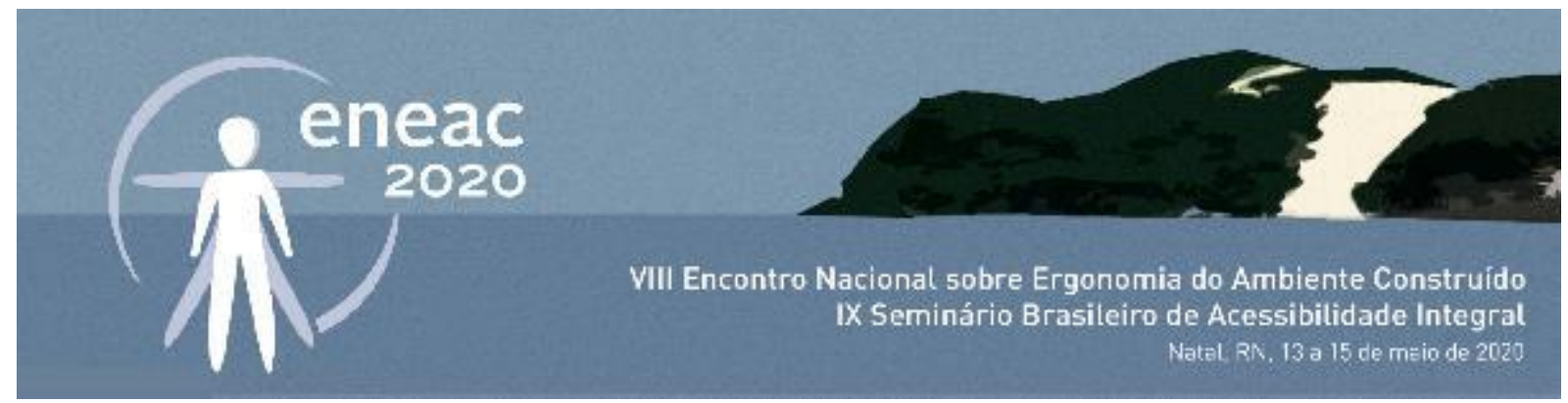

Este local é de importante necessidade para os estudantes, já que se configura como um ambiente de encontro e de socialização. Por isso, deveria ser agradável, aconchegante e tranquilo, além de se adaptar às diferentes necessidades do cotidiano.

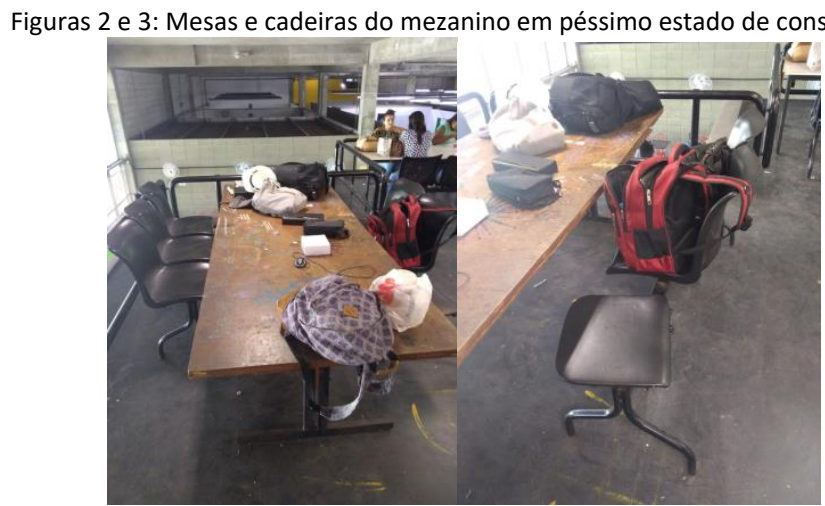

Fonte: Matheus Henrique, 2019.

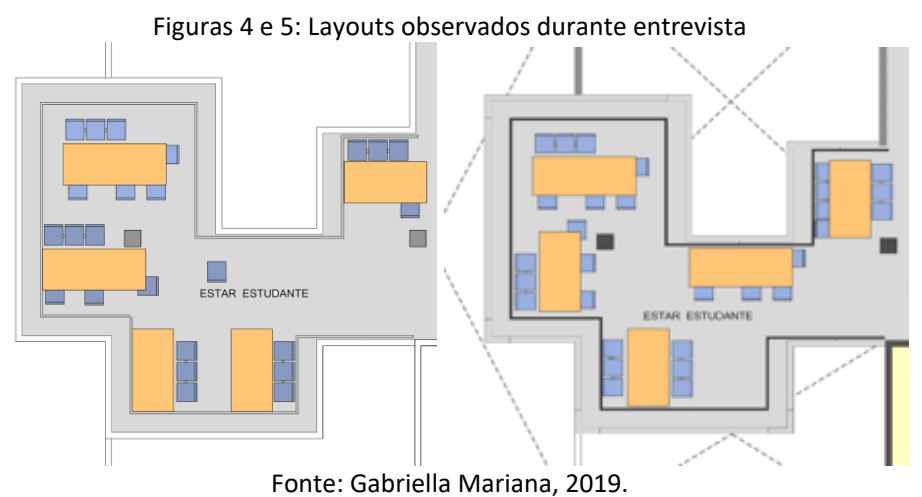

\section{Identificação da configuração ambiental}

Considerando-se as análises ambientais do espaço, constatou-se a precariedade do ambiente quanto ao conforto ambiental - térmico, acústico e lumínico. O conforto está "relacionado a questões psicológicas de identificação e satisfação com o local, assim como a condições físicas de temperatura, umidade, ventilação, iluminação e acústica" (FREITAS, 2005, p. 46). Tomando como base a MEAC (VILLAROUCO, 2008), foram feitas medições de variáveis térmicas, acústicas e lumínicas para se obter valores de comparação, analisá-los e, a partir deles, estabelecer diretrizes para a melhoria do espaço.

Nas medições de variáveis térmicas (Tabela 1), como explicitado na metodologia, foram utilizados os instrumentos termohigrômetro e termo-anemômetro para mensurar a temperatura do ar, a umidade relativa do ar e a velocidade dos ventos no local. Foram escolhidos três pontos (Figura 7) no mezanino para a realização das medições, tomando como critério de seleção a sua disposição no ambiente. Os dados obtidos constatam uma temperatura elevada, cuja média mensurada foi de $30,3^{\circ} \mathrm{C}$ e a máxima de $30,7^{\circ} \mathrm{C}$, mais quente do que na cidade do Recife, com média de $29,3^{\circ} \mathrm{C}$ durante o período da pesquisa (Figura 6). Esses valores são agravados tanto pela umidade do local, que 


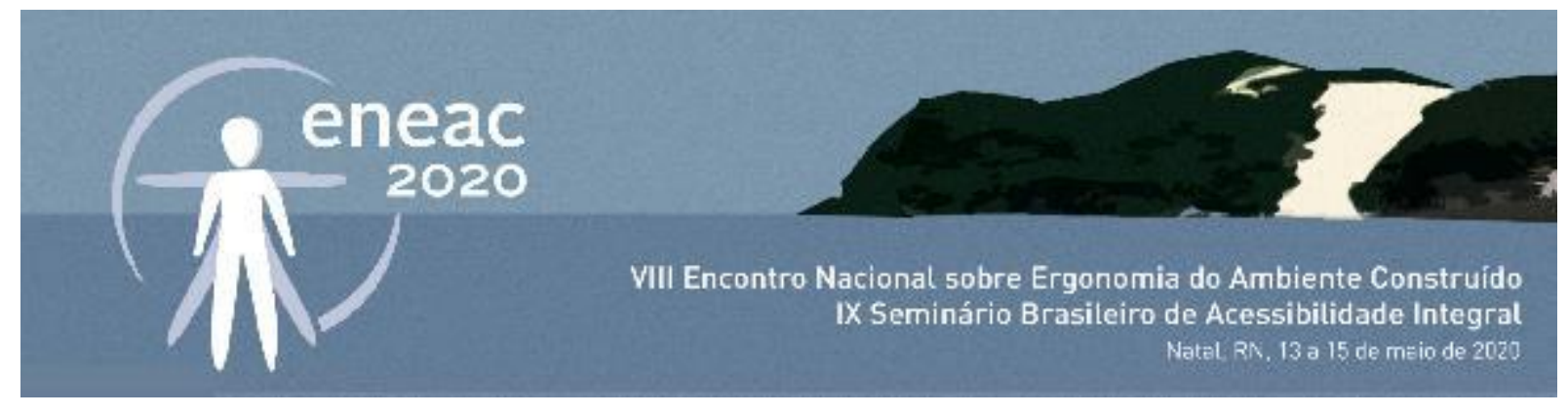

alcançou média de $68,8 \%$ nas medições executadas, como também pela baixa ventilação percebida no local, com picos de $0,2 \mathrm{~m} / \mathrm{s}$. Essa inércia do ar pode ser explicada pelo fato das esquadrias presentes na orientação sul do mezanino serem fechadas permanentemente. O desconforto térmico é potencializado pela existência do restaurante Aquarela, imediatamente abaixo do mezanino, o que aumenta tanto a sensação de desconforto térmico quanto de desconforto acústico.

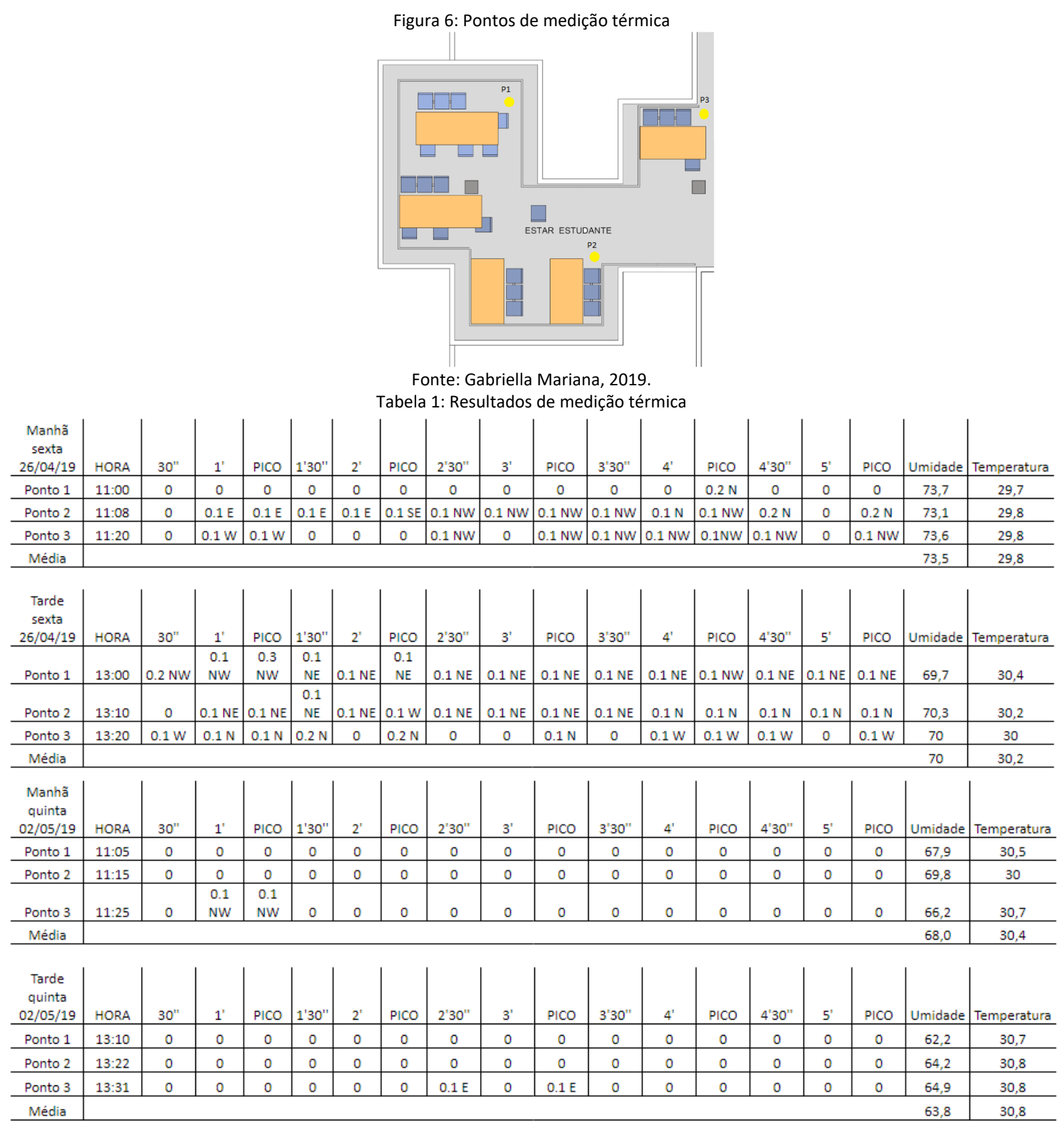

Fonte: Lucas Gomes, 2018. 


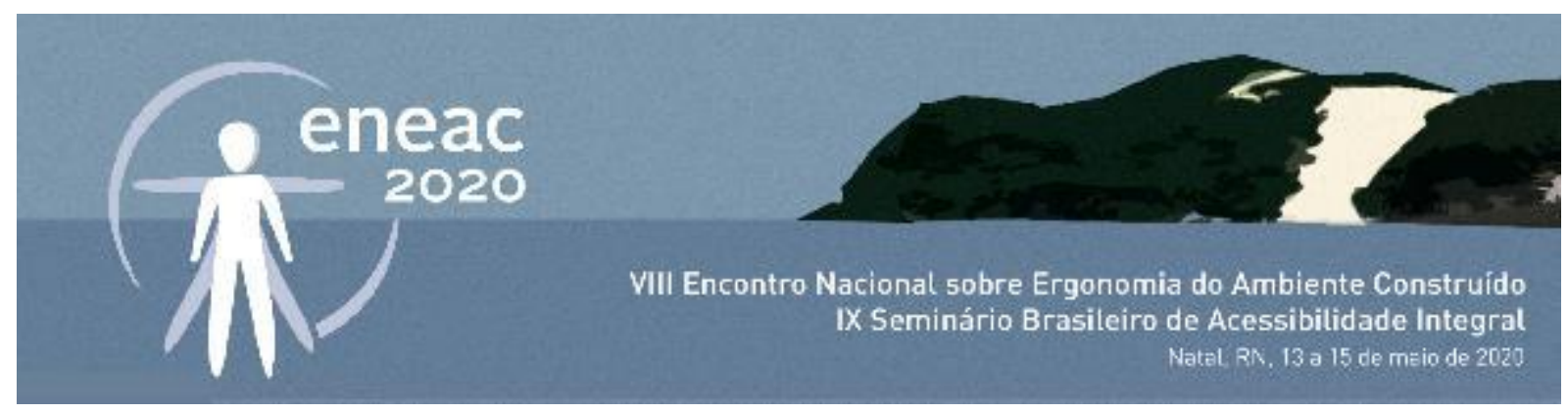

Figura 7: Dados da Estação Automática: Recife (PE)

\begin{tabular}{|c|c|c|c|c|c|c|c|c|c|c|c|c|c|c|c|c|c|c|}
\hline \multirow[t]{2}{*}{ Data } & \multirow{2}{*}{\begin{tabular}{|l} 
Hora \\
UTC \\
\end{tabular}} & \multicolumn{3}{|c|}{ Temperatura $\left({ }^{\circ} \mathrm{C}\right)$} & \multicolumn{3}{|c|}{ Umidade $(\%)$} & \multicolumn{3}{|c|}{ Pto. Orvalho $\left({ }^{\circ} \mathrm{C}\right)$} & \multicolumn{3}{|c|}{ Pressão $(\mathrm{hPa})$} & \multicolumn{3}{|c|}{ Vento $(\mathrm{m} / \mathrm{s})$} & \multirow{2}{*}{\begin{tabular}{|c|} 
Radiação \\
$\left(\mathrm{kJ} / \mathrm{m}^{2}\right)$ \\
\end{tabular}} & \multirow{2}{*}{\begin{tabular}{|l} 
Chuva \\
$(\mathrm{mm})$
\end{tabular}} \\
\hline & & Inst. & Máx. & Mín. & Inst. & Máx. & Mín. & Inst. & Máx. & Mín. & Inst. & Máx. & . & \begin{tabular}{|l|} 
Vel. \\
\end{tabular} & Dir. $\left({ }^{\circ}\right)$ & Raj. & & \\
\hline $26 / 04 / 2019$ & 11 & 28.3 & 28.4 & 25.5 & 86 & 92 & 85 & 25.7 & 26.3 & 23.9 & 1013.9 & 1013.9 & 1013.5 & & & & 2925. & 0.0 \\
\hline $26 / 04 / 2019$ & 12 & 27.9 & 29.6 & 27.9 & 76 & 86 & 73 & 23.4 & 25.9 & 23.2 & 1013.9 & 1014.0 & 1013.9 & & & & 796. & 0.0 \\
\hline $26 / 04 / 2019$ & 13 & 29.5 & 30.1 & 27.7 & 67 & 78 & 65 & 22.7 & 24.5 & 22.5 & 1013.7 & 1014.0 & 1013.7 & 2.1 & 130 & & 403. & 0.0 \\
\hline $02 / 05 / 2019$ & 11 & 29.3 & 29.3 & 24.4 & 85 & 93 & 85 & 26.6 & 26.7 & 23.1 & 1013.3 & 1013.3 & 1012.7 & & & & 1419. & 0.0 \\
\hline $02 / 05 / 2019$ & 12 & 30.1 & 30.2 & 28.3 & 64 & 86 & 64 & 22.6 & 26.5 & 22.6 & 1013.7 & 1013.7 & 1013.4 & 2.2 & 123 & & 1954. & 0.0 \\
\hline $02 / 05 / 2019$ & 13 & 30.4 & 31.3 & 29.8 & 60 & 65 & 55 & 21.7 & 23.3 & 21.0 & 1013.7 & 1013.8 & 1013.7 & 1.8 & 106 & 5.3 & 3102. & 0.0 \\
\hline
\end{tabular}

Fonte: INMET. Disponível em: <http://www.inmet.gov.br/sonabra/pg dspDadosCodigo sim.php?QTMwMQ $\Rightarrow$. Acesso em: 24/01/2020

$\mathrm{Na}$ análise acústica (Tabela 2), foram utilizados os mesmos três pontos escolhidos para as medições de variáveis térmicas (Figura 5), foram usados como referência os níveis de ruído definidos pela NBR 10152/1987 e o decibelímetro, para as medições. Tendo como base que o mezanino foi proposto originalmente como espaço de estar, utilizamos para a análise o valor referente a esse espaço na Norma, que estabelece que o espaço é confortável acusticamente para um intervalo entre 40 e 50 $\mathrm{dB}(\mathrm{A})$. Foram medidos picos de até $84,6 \mathrm{~dB}(\mathrm{~A})$ e média de $70,7 \mathrm{~dB}(\mathrm{~A})$, configurando o mezanino como espaço desconfortável em termos acústicos. Assim, as atividades realizadas no espaço são prejudicadas, além da própria estadia se tornar desconfortável para os usuários. Esses valores se devem, como já comentado, em virtude da localização do mezanino sobre o restaurante, que tem picos de movimentação entre $10 \mathrm{~h} 00$ e $14 \mathrm{~h} 00$, mas também devido à sua proximidade com corredores e escadas de grande fluxo no prédio. Vale salientar, também, a existência de obras, cujos ruídos da parte exterior do edifício reverberam através das esquadrias e contribuem para o desconforto acústico.

\begin{tabular}{|c|c|c|c|c|c|c|c|c|c|c|c|c|}
\hline $\begin{array}{c}\text { Manhã sexta } \\
26 / 04 / 19 \\
\end{array}$ & Hora & $30^{\prime \prime}$ & $1^{\prime}$ & 1'30" & $2^{\prime}$ & $2^{\prime} 30^{\prime \prime}$ & $3^{\prime}$ & 3'30" & $4^{\prime}$ & $4^{\prime} 30^{\prime \prime}$ & $5^{\prime}$ & MÉDIA \\
\hline Ponto 1 & $11: 00$ & 65,3 & 66,3 & 65,4 & 71,2 & 68,3 & 70,5 & 72,1 & 67,3 & 65,1 & 66,6 & 67,81 \\
\hline Ponto 2 & $11: 08$ & 72 & 68,2 & 63,4 & 67,6 & 66,7 & 69,7 & $65,7 \mid$ & 67,3 & 62,5 & 70,4 & 67,35 \\
\hline Ponto 3 & $11: 20$ & 72,1 & 70 & 60,2 & 68,2 & 68 & 67,9 & \begin{tabular}{|c|}
69,9 \\
\end{tabular} & 70,3 & 67,3 & 66,5 & 68,04 \\
\hline $\begin{array}{c}\text { Tarde sexta } \\
26 / 04 / 19 \\
\end{array}$ & Hora & $30^{\prime \prime}$ & $1^{\prime}$ & 1'30" & $2^{\prime}$ & $2^{\prime} 30^{\prime \prime}$ & $3^{\prime}$ & 3'30" & $4^{\prime}$ & $4^{\prime} 30^{\prime \prime}$ & $5^{\prime}$ & MÉDIA \\
\hline Ponto 1 & $13: 00$ & 69,1 & 70,2 & 69,1 & 71,9 & 70,2 & 71,2 & \begin{tabular}{|l|}
76,4 \\
\end{tabular} & 68,8 & 83,2 & 66,9 & 71,7 \\
\hline Ponto 2 & $13: 10$ & 70,3 & 71,3 & 72,1 & 70,2 & 67,8 & 70,2 & \begin{tabular}{|l|}
65,9 \\
\end{tabular} & 75,8 & 75,6 & 70,6 & 70,98 \\
\hline Ponto 3 & $13: 20$ & 71,7 & 65,7 & 69,3 & 65,9 & 64,9 & 78,8 & \begin{tabular}{|l|}
65,9 \\
\end{tabular} & 73,8 & 76,5 & 78,1 & 71,06 \\
\hline $\begin{array}{c}\text { Manhã } \\
\text { quinta } \\
02 / 05 / 19\end{array}$ & Hora & $30^{\prime \prime}$ & $1^{\prime}$ & $1^{\prime} 30^{\prime \prime}$ & $2^{\prime}$ & $2^{\prime} 30^{\prime \prime}$ & $3^{\prime}$ & $3^{\prime} 30^{\prime \prime}$ & $4^{\prime}$ & $4^{\prime} 30^{\prime \prime}$ & $5^{\prime}$ & MÉDIA \\
\hline Ponto 1 & 11:05 & 75,6 & 72,8 & 72,1 & 70,3 & 78 & 71,2 & 70,3 & 74,4 & 74,4 & 71,3 & 73,04 \\
\hline Ponto 2 & $11: 15$ & 56,4 & 75,6 & 71,4 & 71,4 & 72,7 & 71,4 & 71,8 & 73,7 & 71,5 & 75,3 & 71,12 \\
\hline Ponto 3 & $11: 25$ & 73,9 & 75,3 & 68,6 & 70,5 & 75,1 & 74,4 & 73,2 & 74,6 & 74,1 & 72,6 & 73,23 \\
\hline $\begin{array}{c}\text { Tarde quinta } \\
02 / 05 / 19\end{array}$ & Hora & $30^{\prime \prime}$ & $1^{\prime}$ & $1^{\prime} 30^{\prime \prime}$ & $2^{\prime}$ & $2^{\prime} 30^{\prime \prime}$ & $3^{\prime}$ & $3^{\prime} 30^{\prime \prime}$ & $4^{\prime}$ & $4^{\prime} 30^{\prime \prime}$ & $5^{\prime}$ & MÉDIA \\
\hline Ponto 1 & $13: 10$ & 70,3 & 65,5 & 70,4 & 69,3 & 68,8 & 73,1 & 70,9 & 71,8 & 72,1 & 72,2 & 70,44 \\
\hline Ponto 2 & $13: 22$ & 73,1 & 74,6 & 73 & 71,3 & 74,3 & 72,6 & 84,6 & 71,8 & 73,4 & 70,2 & 73,89 \\
\hline Ponto 3 & $13: 31$ & 76,9 & 70,8 & 65,9 & 67,1 & 65,2 & 68,1 & \begin{tabular}{|l|} 
\\
\end{tabular} & 70,3 & 69,8 & 71,2 & 69,24 \\
\hline
\end{tabular}

Fonte: Lucas Gomes, 2019. 


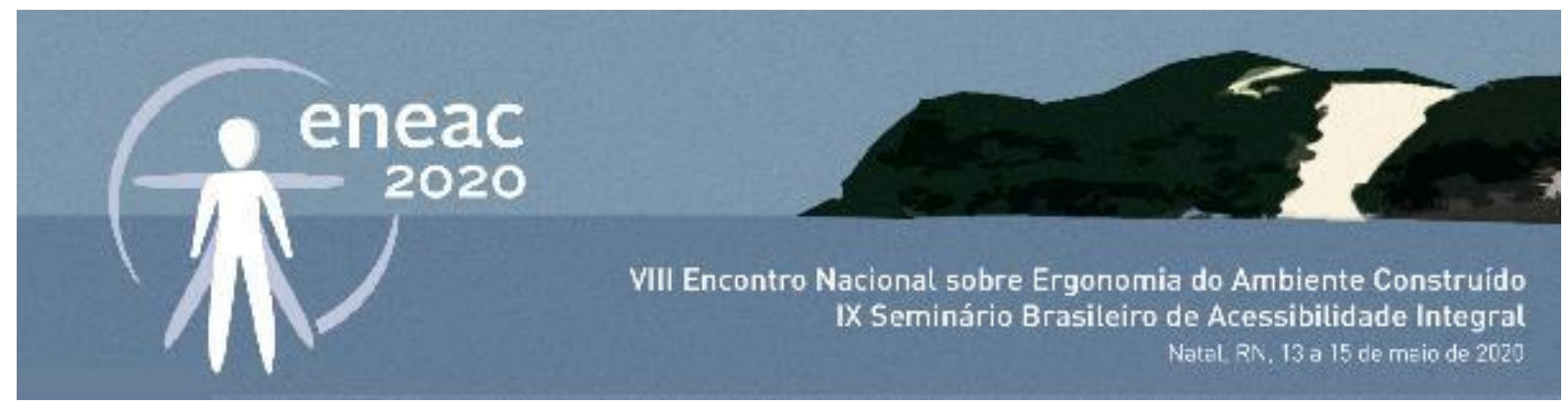

$\mathrm{Na}$ análise do nível de iluminamento (Tabela 3), foi utilizada a norma NBR 5413/1992 para estabelecer os níveis adequados para o ambiente, que tratamos como espaço de circulação e selecionamos as mesas como ponto de medições (Figura 8). Os 150 lux estabelecidos por norma foram atendidos de forma geral pelo ambiente, que teve média de 211 lux de iluminamento. Todavia, vale ressaltar que os resultados obtidos das medições variaram muito entre as mesas de reunião/estudo. Enquanto em determinada mesa obteve-se 65 lux, em outra, foram medidos 293 lux de iluminamento, resultados que salientam a má disposição das mesas em relação às fontes de luz.

Diferentemente do esperado, não houve uma tendência de mais iluminamento em mesas mais próximas às aberturas para o exterior, o que aponta que a iluminação natural é bem distribuída por todo o ambiente, atendendo à finalidade de estar para a qual o mezanino foi projetado. A iluminação artificial, por sua vez, corrobora para os diferentes níveis de iluminamento no ambiente, já que as mesas não seguem a disposição das luminárias. As cores e as texturas do ambiente interferem diretamente no conforto lumínico, o concreto aparente ressalta a penumbra no espaço e o vermelho das paredes causa cansaço à visão, dificultando a estadia no local.

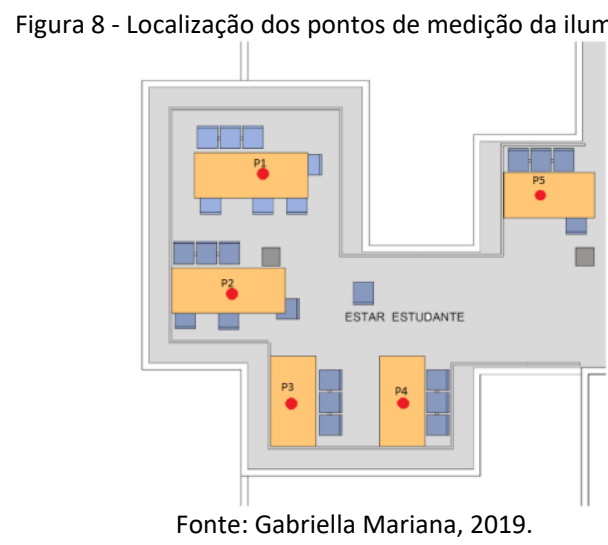

\begin{tabular}{|c|c|c|c|c|}
\hline $\begin{array}{l}\text { MEDIÇÃO } \\
\text { LUMÍNICA }\end{array}$ & $\begin{array}{c}26 / 04 \\
11 \mathrm{~h}-12 \mathrm{~h} \\
\end{array}$ & $\begin{array}{c}26 / 04 \\
13 h-14 h \\
\end{array}$ & $\begin{array}{c}02 / 05 \\
11 \mathrm{~h}-12 \mathrm{~h} \\
\end{array}$ & $\begin{array}{c}02 / 05 \\
13 h-14 h\end{array}$ \\
\hline Ponto 1 & 215 & 155 & 192 & 106 \\
\hline Ponto 2 & 102 & 190 & 107 & 65 \\
\hline Ponto 3 & 280 & 330 & 294 & 293 \\
\hline Ponto 4 & 280 & 265 & 266 & 233 \\
\hline Ponto 5 & 221 & 226 & 228 & 189 \\
\hline
\end{tabular}

Fonte: Lucas Gomes, 2019.

\section{Avaliação do ambiente em uso}

Foram realizadas diversas visitas, em diferentes horários, em dias de aula. 0 que se constatou é que existe um intenso fluxo de pessoas, principalmente, entre 7:00 horas e 8:00 horas da manhã, período antes do início das aulas do turno matutino e entre 12:00 horas e 14:00 horas, visto que esse período antecede o início das aulas do turno da tarde e também é o horário de almoço, no qual os estudantes utilizam as mesas e os aparelhos microondas disponíveis nos DAs, para esquentar suas refeições. Além disso, o ambiente fica mais ruidoso também por conta da movimentação intensa do 


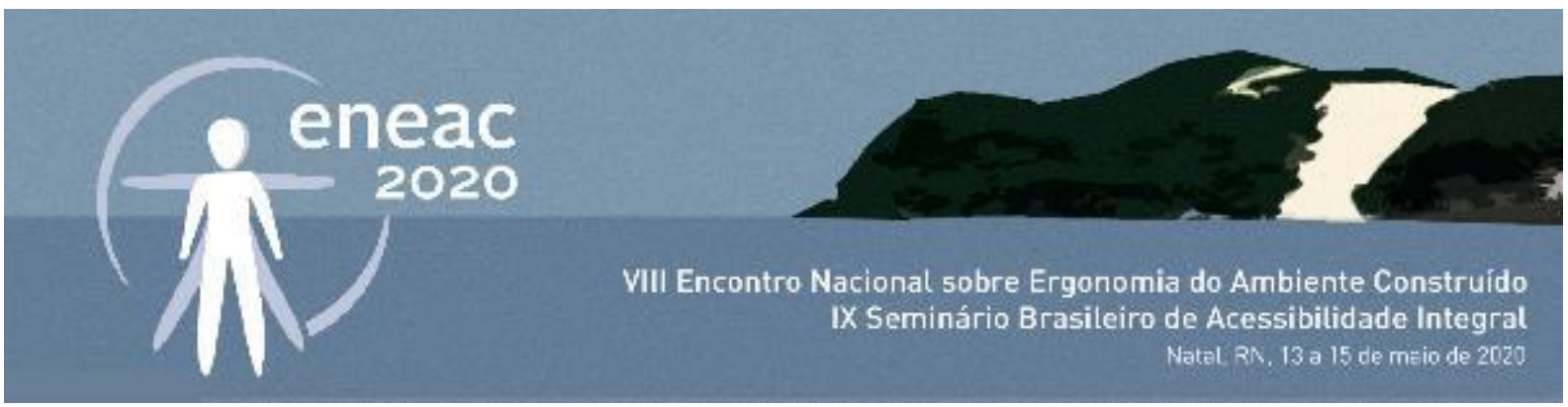

Restaurante Aquarela, localizado imediatamente abaixo do mezanino (Figura 9). Em consequência do uso do ambiente para a realização de refeições, o mesmo tende a ficar sujo e consequentemente desagradável. Os lixeiros, que são pequenos, costumam ficar cheios e as mesas, com resto de alimentos e embalagens, decorrentes da pouca quantidade de lixeiros associada ao mau uso dos estudantes.

Após o período de almoço, o ambiente volta a ser tranquilo e geralmente é utilizado como espaço de convivência e estudo em grupo. À noite, o ambiente permanece calmo e geralmente é o período onde o mezanino se encontra mais sujo, visto que os resíduos do dia inteiro, como embalagens, papéis, cigarros, restos de comida etc., se acumulam nas mesas, no chão e nos lixeiros.

Nos horários de pico, a quantidade de cadeiras não é suficiente para atender a quantidade de usuários, além de que muitas das cadeiras existentes atualmente no local estão quebradas, sendo muitas delas "reaproveitadas" de outros locais do Centro de Artes e Comunicação e deixadas no Mezanino. A sujeira do local também acaba tornando-o inadequado para refeições.

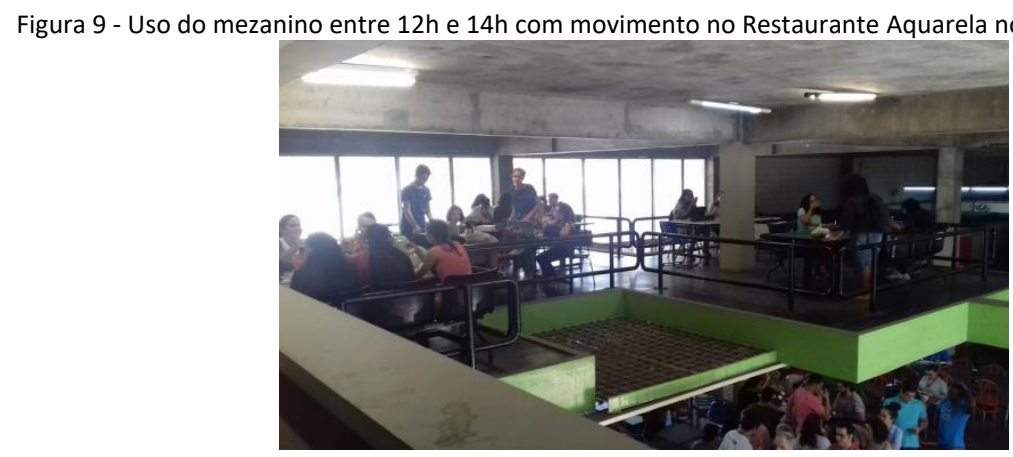

Fonte: Matheus Henrique, 2019.

$\mathrm{O}$ alto fluxo de pessoas se deve ao fato de que, no mesmo andar, existem quatro salas que abrigam os diretórios acadêmicos dos cursos do CAC, além da proximidade com os banheiros e com uma das principais circulações de acesso ao térreo e demais pavimentos do edifício (Figura 10). 

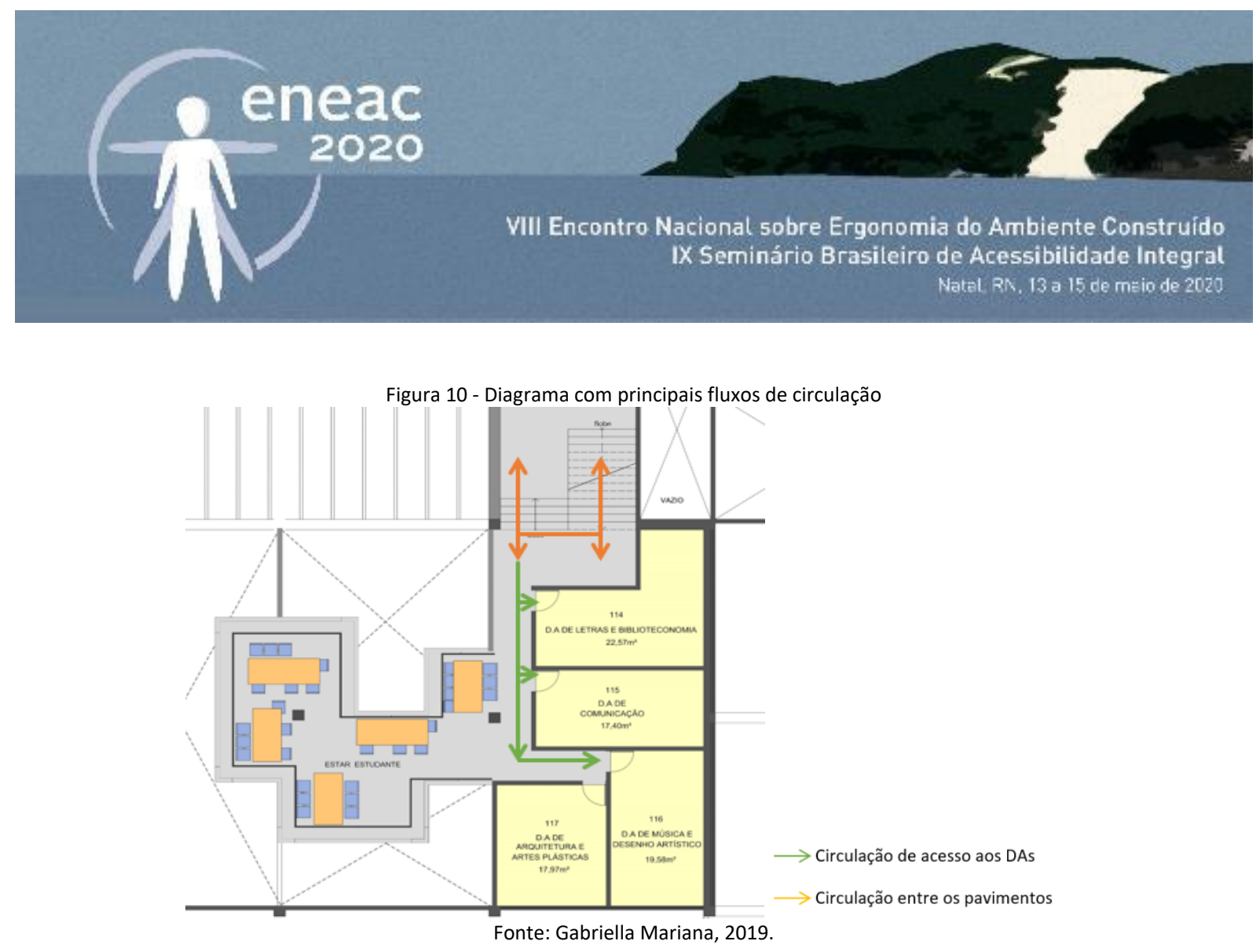

Com relação à análise do ambiente em uso, foi observado que uma grande diversidade de atividades é realizada no local. Como ficou constatado nos formulários realizados, a maior parte dos usuários se utiliza do espaço para estudo, seguido dos que utilizam-no como espaço de estar. O uso como espaço para realização de refeições também é marcante (Gráfico 1). É válido ressaltar que este espaço foi concebido como um espaço de estar, e mesmo não sendo apropriado, é como espaço de estudos que é mais utilizado (Figuras 11 e 12).

Gráfico 1 - Uso do mezanino de acordo com os usuários entrevistados

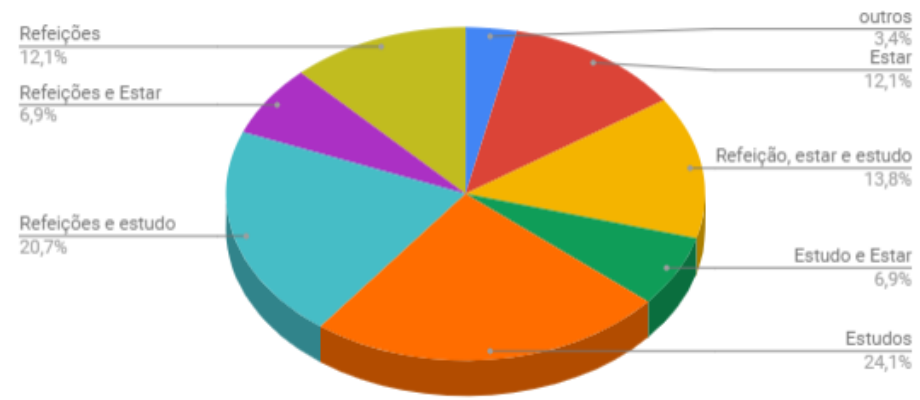

Fonte: Thais Santos, 2019.

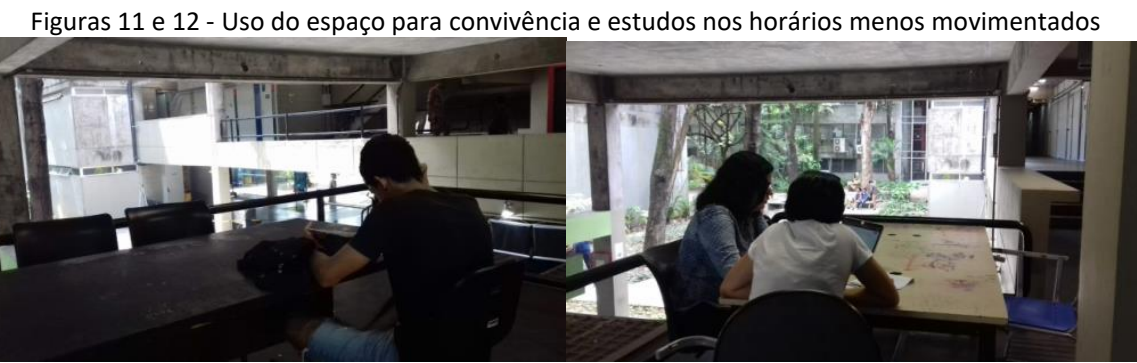

Fonte: Matheus Henrique, 2019. 


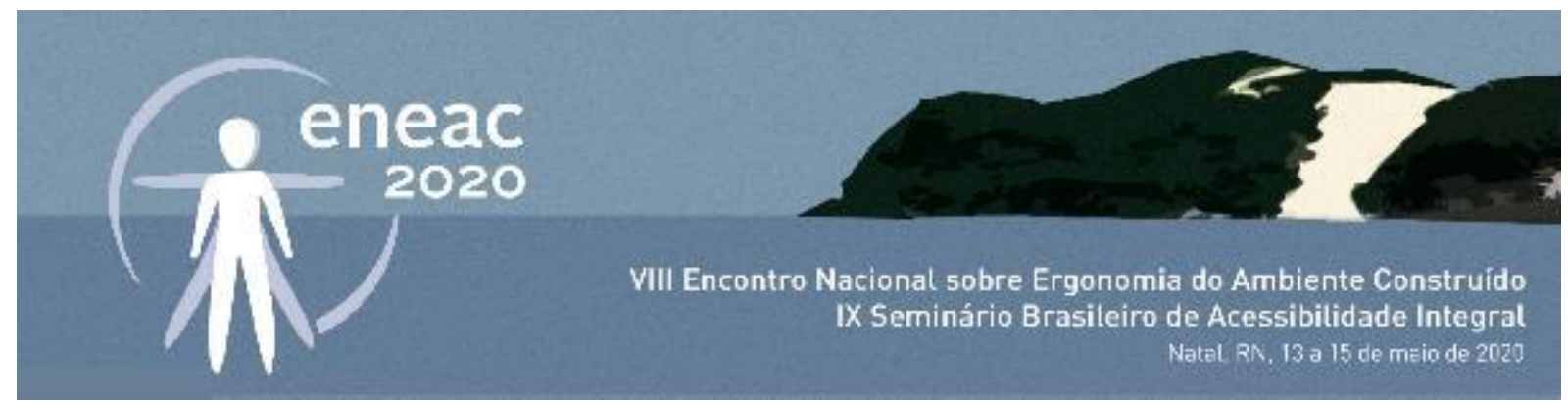

\section{Percepção ambiental do usuário}

Com a aplicação dos formulários, foi possível saber da opinião dos usuários do ambiente. As duas perguntas permitiram que se comparasse a situação real e a situação ideal, na perspectiva do usuário.

Pergunta 1: Quais ideias ou imagens se passam na sua mente quando você pensa no Mezanino do CAC? (Gráfico 2)

Gráfico 2 - Atributos do mezanino do CAC a partir do usuário

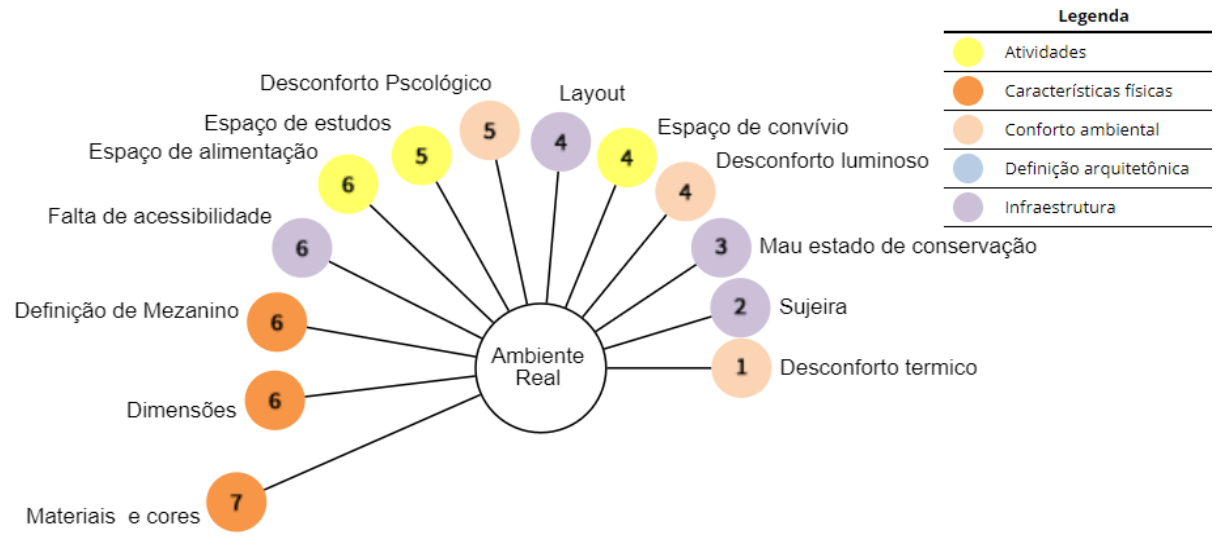

Fonte: Antônio Neto, 2019.

$\mathrm{Na}$ análise do ambiente em sua configuração real, as respostas dos usuários obtidas pelos formulários foram negativas, em sua maioria. A alta sensação de desconforto térmico e as cores ofuscantes do ambiente estão entre os principais problemas apontados pelos usuários. $O$ desconforto psicológico foi muito reclamado, algo que é resultado da associação dos demais problemas do espaço. Na infraestrutura, vale ressaltar a sujeira, que é reflexo das poucas e pequenas lixeiras do local, e o mau estado de conservação do mobiliário do ambiente, como cadeiras quebradas e mesas riscadas, fruto da má utilização dos usuários do ambiente. A configuração do layout também foi alvo de críticas (Gráfico 3), pois inviabiliza o melhor aproveitamento do espaço e gera situações onde, foi observado, por exemplo, pessoas saltando por cima de outras sentadas para se sentar nas cadeiras vazias com acesso obstruído. A falta de acessibilidade do local foi outro ponto observado, já que impossibilita o acesso dos estudantes com restrições físico-motoras.

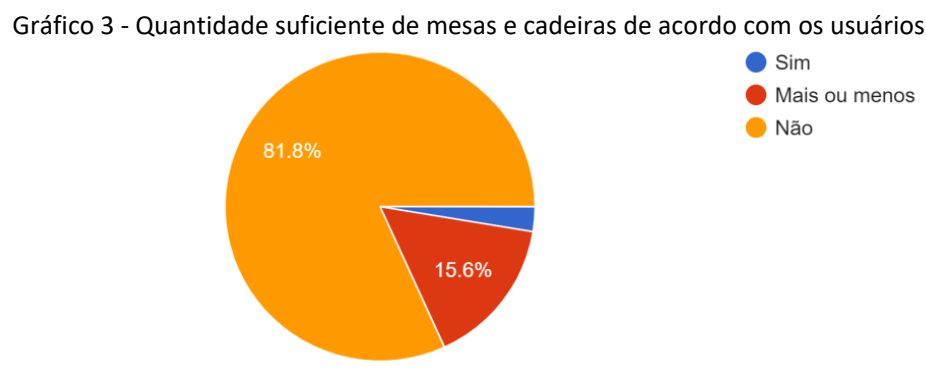

Fonte: Thais Santos, 2019. 


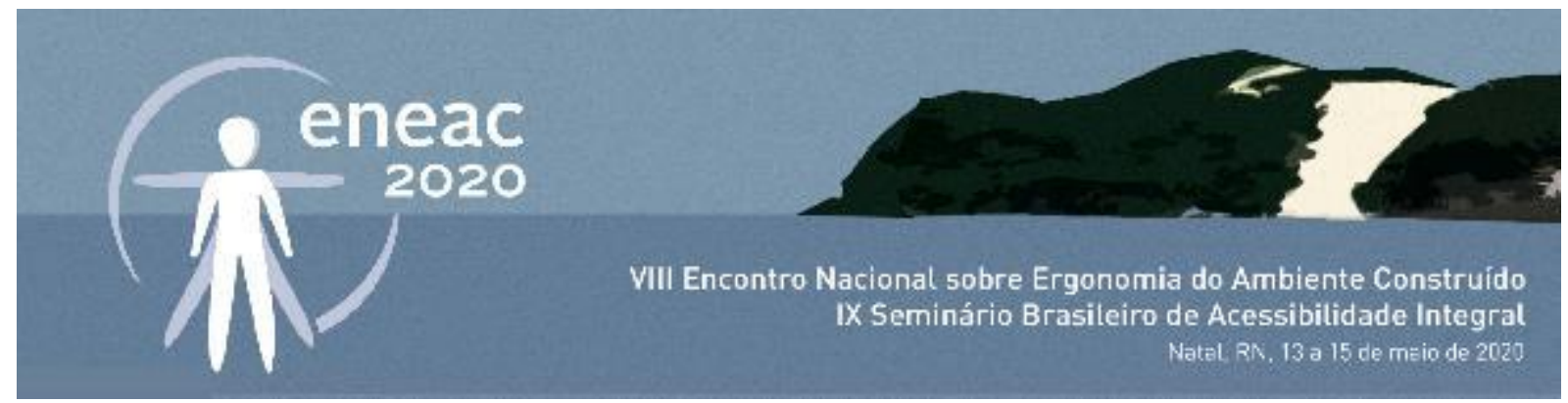

As atividades que ocorrem no mezanino foram muito citadas, mas o caráter de espaço de convívio foi o que se sobressaiu. Todavia, ainda é marcante a sua configuração como espaço de estudos, função esta que não corresponde ao programa do projeto, o que acaba gerando desconforto para os estudantes que se utilizam do espaço com essa finalidade - pois os níveis de iluminamento são insuficientes para a realização de estudo e leitura. Também foi muito citado como espaço de alimentação, havendo ainda os usuários que destacaram negativamente as características físicas do mezanino, como suas dimensões, materiais, como concreto aparente, e suas cores.

Fica perceptível, após a análise, a insatisfação dos usuários com o ambiente que deveria ser um lugar aconchegante e confortável, um verdadeiro ponto de encontro para os estudantes do CAC. Foi realizada uma nova constelação de atributos, incitando os usuários a responder sobre um mezanino ideal.

Pergunta 2: Quais ideias ou imagens se passam na sua mente quando você pensa em um Mezanino do CAC ideal? (Gráfico 4)

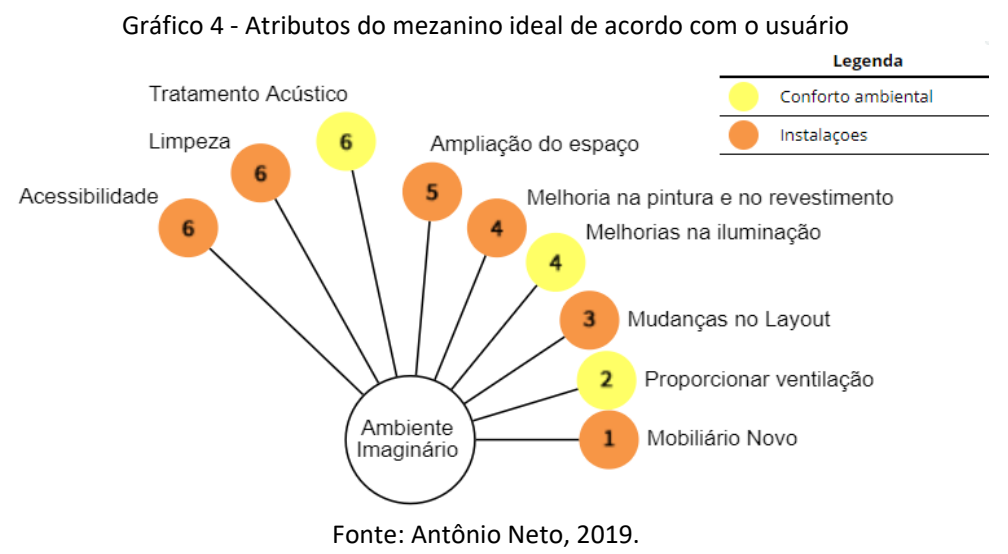

As soluções apontadas pelos usuários e sistematizadas no quadro anterior abordam a acessibilidade e limpeza, respondendo aos problemas apontados no Gráfico 3, mas são apontadas algumas necessidades mais específicas, como tratamento acústico e a melhoria da pintura e do revestimento, já que algumas cores escolhidas na pintura acabam cansando a visão. Foram sugeridas mudanças no layout do ambiente, melhoria da ventilação visando a uma amenização no desconforto térmico e a aquisição de mobiliários novos. Também foram citadas a melhoria da iluminação, já que o espaço é utilizado como local de estudo, apesar de existir espaços mais apropriados no centro para a realização dessa atividade, a exemplo da biblioteca, além da ampliação do espaço, que se restringiu a um pequeno número de usuários.

\section{Diagnóstico ergonômico do ambiente}

O mezanino do CAC se apresenta como um importante ponto de encontro entre os estudantes, proporcionando o convívio coletivo para a realização das mais diversas atividades. Acrescentado a isso, o ambiente promove visadas para o jardim interno, e como se encontra em um espaço de transição entre os pavimentos, é possível que seja visto de diversos pontos do edifício, garantindo a 


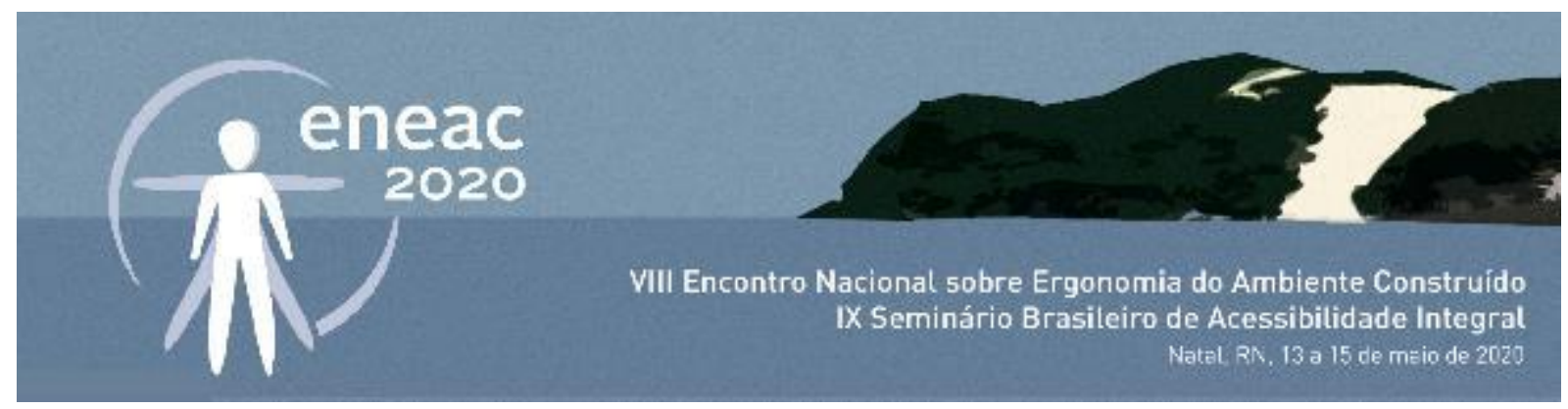

sua integração visual com o restante do CAC. Essas características reforçam o seu potencial e importância para o funcionamento do edifício, de modo geral.

Entretanto, a partir das análises das configurações físicas do ambiente e das percepções dos usuários com relação a ele, de um modo geral, é possível afirmar que o mezanino do CAC não cumpre com suas funções atuais de uso de forma satisfatória, visto que algumas atividades ali realizadas, como estudo, desenhos técnicos e trabalhos manuais, são inadequadas para qual o ambiente foi projetado, sobrecarregando-o.

Sob o ponto de vista da percepção dos usuários, consultados por meio dos formulários de resposta eletrônica, e com as análises ambientais realizadas, essa inadequação deriva de problemas associados às questões térmica, lumínica, acústica, de layout e de mobiliário, evidenciados com: a presença do restaurante Aquarela, abaixo do Mezanino, cujo funcionamento da cozinha proporciona a transferência de calor por radiação, elevando a temperatura ambiente e a sensação térmica, temse ainda os elevados ruídos provenientes dos usuários do restaurante e do funcionamento da cozinha; esquadrias laterais permanentemente fechadas que impedem a ventilação cruzada no ambiente; layout e tipo do mobiliário, em péssimo estado de conservação, em desalinho com a posição das luminárias; manutenção prejudicada por lixeiras insuficientes e descaso por parte dos usuários com relação à limpeza do ambiente; guarda-corpo com altura abaixo das dimensões mínimas e a falta de equipamentos que promovam acessibilidade, esses dois últimos se encontrando em desacordo com o que é previsto por suas respectivas normas.

\section{PROPOSTA DE INTERVENÇÃO}

Visto a sua função principal como espaço de convivência e a gama de problemáticas no ambiente, surge a necessidade de mudanças imediatas, como a adequação com as normas vigentes e as melhorias no conforto ambiental. São elas: abertura das esquadrias laterais ao mezanino, para que seja proporcionada a ventilação cruzada no ambiente, amenizando o impacto das altas temperaturas; correção do layout do mobiliário (Figura 13), adequando-o para garantir a acessibilidade, instalação de sistema de iluminação artificial localizada sobre as mesas, para melhor conforto do usuário na realização das suas atividades de estudo e a utilização de cores neutras e amenas nas paredes do ambiente, , para que atenda satisfatoriamente às questões de lumínica; tratamento acústico no teto e nas paredes da cozinha do Aquarela, , além da utilização de painéis acústicos no teto do mezanino para a redução da propagação dos altos níveis de ruído.

A instalação de novos mobiliários como mesas fixas ao piso com alturas apropriadas para o uso de computadores e para refeições (Figuras 14 e 15), implantação de cadeiras adequadas e lixeiras novas; elevação da altura do guarda-corpo de $90 \mathrm{~cm}$ para $110 \mathrm{~cm}$, para que se adeque às normas vigentes; para promoção de acessibilidade, se faz necessária a criação de equipamentos que conectem o mezanino ao 1ㅇ pavimento, por meio do elevador de acessibilidade, localizado próximo às escadas existentes e aos Diretórios Acadêmicos (Figura 16). Esta opção foi adotada devido ao fato de que a construção de uma rampa acessível acarretaria numa grande descaracterização do edifício, devido à grande dimensão desta, comprometendo sua estética, o passeio arquitetônico que ele promove e as visadas, grandes marcos do CAC. Dessa forma, apesar dos elevadores não serem 


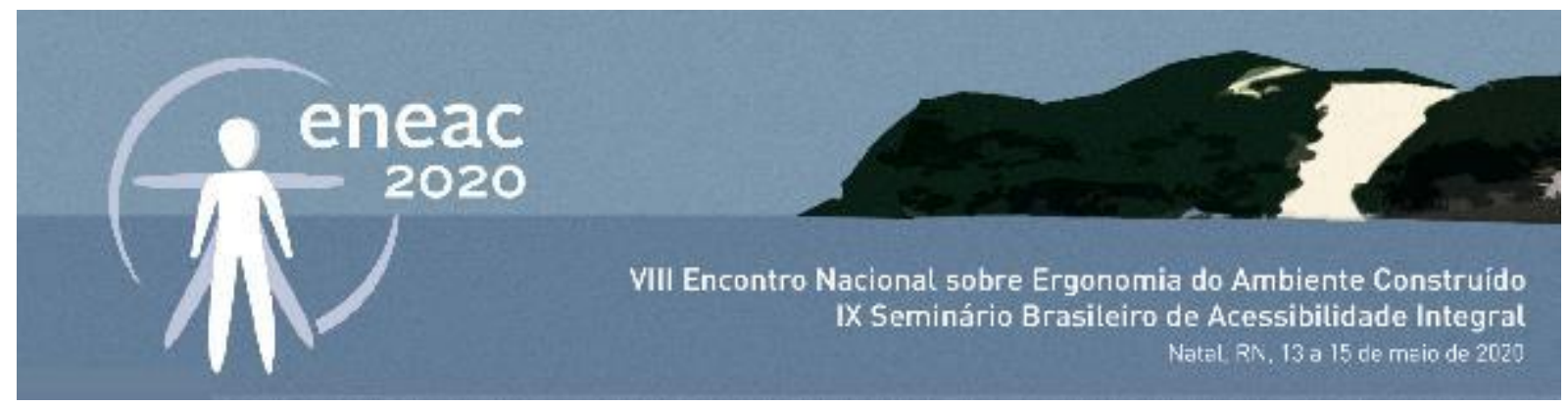

sempre eficientes visto que numa possível falta de energia e/ou quebra do equipamento a acessibilidade seria comprometida, ainda é a melhor e mais viável opção.

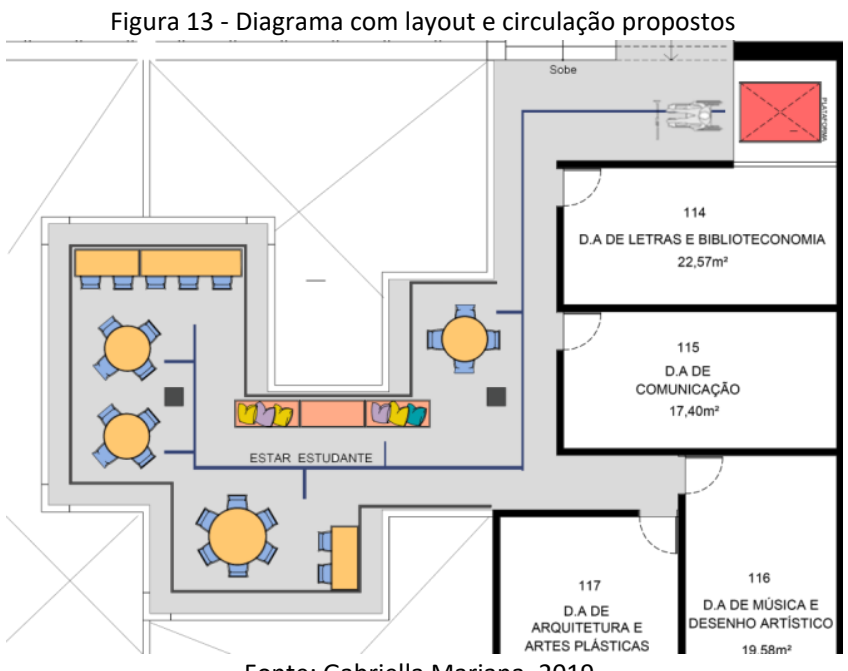

Fonte: Gabriella Mariana, 2019.

Figuras 14 e 15 - Modelo de mobiliário sugerido

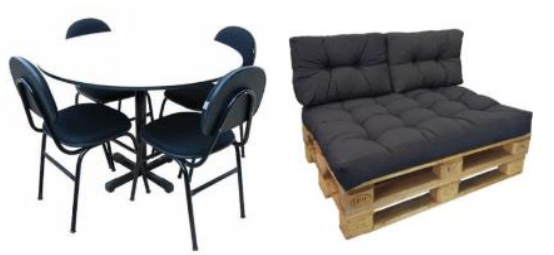

Fonte:https://www.mjoffice.com.br/product/conj-mesa-para-sala-de-leitura-com-4-cadeiras-2/;

http://ballconydesign.decorvintage.tk/2019/08/01/proheim-outdoor-pallet-cushion-tino-lounge-set-in-anthracite-seat-cushion-120-x-80-x18-cm-2-back-cushions-60-x-40-x-10-20-cm-lounge-pallet-sofa-indoor-outdoor-dirt-and-water-repellent-pallet. Acesso em: jan.2020.

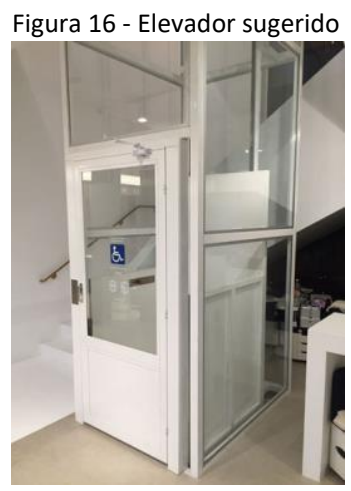

Fonte: http://www.mobileautomacao.com.br/elevador-cadeirante. Acesso em: jan.2020.

\section{Agradecimentos}

Gostaríamos de agradecer a Lucas Gomes e a Gabriella Mariana, graduandos em Arquitetura e Urbanismo e a Jaucele Azerêdo, docente da disciplina Ergonomia do Ambiente Construído, ministrada na graduação em Arquitetura e Urbanismo da Universidade Federal de Pernambuco, pelo 


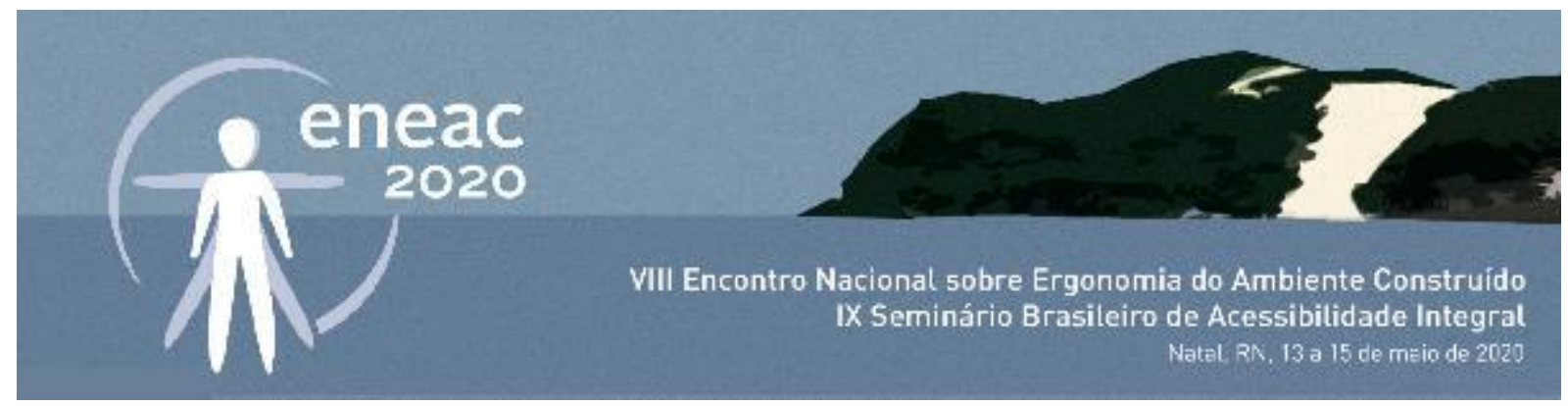

apoio, auxílio e incentivo nas medições e produção de conteúdo gráfico deste artigo, que foram fundamentais para os resultados apresentados.

\section{REFERÊNCIAS}

ABNT. ASSOCIAÇÃO BRASILEIRA DE NORMAS TÉCNICAS. NBR 10152: Níveis de ruído para conforto acústico. Rio de Janeiro, 1987.

ABNT. ASSOCIAÇÃO BRASILEIRA DE NORMAS TÉCNICAS. NBR 5413: Iluminância de interiores. Rio de Janeiro, 1992.

ABNT. ASSOCIAÇÃO BRASILEIRA DE NORMAS TÉCNICAS. NBR 14718: Guarda-corpos para edificação. Rio de Janeiro, 2001.

EKAMBI-SCHMIDT, J, La Percepción del hábitat, Gili, Barcelona, 1974.

FREITAS, R.. O que é conforto. In: VIII Encontro Nacional e IV Encontro Latino Americano Sobre Conforto no Ambiente Construído, 2005, Maceió - AL. Anais do VIII Encontro Nacional e IV Encontro Latino Americano Sobre Conforto no Ambiente Construído, 2005. p. 726-735. Disponível em: https://ruskinfreitas.files.wordpress.com/2010/08/o-que-c3a9conforto.pdf. Acesso em: nov/2018.

MOLES, A, Sociodynamique de la culture, Paris, Mouton, 1973.

VILLAROUCO, V. Construindo uma metodologia de avaliação ergonômica do ambiente - AVEA. Anais do 140 Congresso Brasileiro de Ergonomia. Porto Seguro: ABERGO, 2008.

VILLAROUCO, Vilma. Tratando de ambientes ergonômicamente adequados: Seriam Ergoambientes?. In: Cláudia Mont'Alvão; Vilma Villarouco. (Org.). Um novo olhar para o projeto: a ergonomia no ambiente construído. 01 ed. Teresópolis - RJ: 2AB, 2011, v. Único, p. 25-46. 